\title{
Influence of slag content and water-binder ratio on leaching behavior of cement pastes
}

\author{
Yu-Juan Tang, Xiao-Bao Zuo *, Shao-Li He, Olawale Ayinde, Guang-Ji Yin \\ Department of Civil Engineering, Nanjing University of Science \& Technology, Nanjing, 210094, P.R.China
}

\begin{abstract}
In order to obtain quickly the influences of blast furnace slag and water-binder ratio on the leaching behavior of cement-based material and its corrosion resistance in water environments, an accelerated calcium leaching experiment on a slice specimen with slag-cement pastes in $6 \mathrm{M} \mathrm{NH}_{4} \mathrm{Cl}$ solution was carried out. Using the saturation-drying weighing method, $\mathrm{X}$-ray diffraction (XRD) and the scanning electron microscope (SEM/EDS) measurement, the influences of water-binder ratio and slag content on the porosity, phase composition, microstructure morphology and Calcium-Silicon ratio of slag-cement pastes in the process of calcium leaching were analyzed. Results show that, compared to cement pastes without slag, the slag-cement paste with the appropriate slag content has a low rate of microstructure deterioration and a good leaching resistance. The optimum slag contents in slag-cement pastes are respectively $40 \%$ and $50 \%$ corresponding to the low and high water-binder ratio. The porosity, Calcium-Silicon ratio and microstructure morphology of slag-cement pastes exhibit small change in the process of accelerating leaching, and this indicates that the slag-cement pastes with the optimum slag content can provide the best performance of calcium leaching resistance in the soft-water environment.
\end{abstract}

Keywords: Slag-cement pastes; slag content; water-binder ratio; calcium leaching; porosity; XRD; SEM

\section{Introduction}

Concrete structures such as dams, ports, bridges and pipelines, located in rivers, lakes and other water environments, are easily corroded by soft water, causing the material durability deterioration and structural performance reduction of concrete [1-3]. Under the attack of water environment, the dissolved calcium ions in pore solution from the cement hydration products $\mathrm{Ca}(\mathrm{OH})_{2}$ and C-S-H gel in concrete flow into the water due to the great gradient of the calcium ion concentration, and this phenomenon, which is called the calcium leaching, leads to the reduction of the calcium content in concrete, the decrease of alkalinity of the pore solution and the increase of porosity of concrete [4-7]. Calcium leaching also causes the reduction of

\footnotetext{
* Corresponding auther. Tel: +862584315773.

E-mail:xbzuo@sina.com (Xiao-Bao Zuo).
} 
concrete strength, the increase of concrete permeability, and weakens the protective effects of concrete on steel bar [6,8]. Water attack is one of the important environmental factors leading to the durability degradation of concrete structures $[9,10]$. Both the blast furnace slag mixed in concrete and the reduction in water-binder ratio can improve its microstructures, also increase the calcium leaching resistance of concrete in water environment [11-17].

Recently, some advanced studies on the influence of slag on the hydration characteristics and the microstructure evolution of cement-based materials have been conducted [18-22]. Lumley [18] studied the influences of curing age, slag content and water-binder ratio on the hydration degree of slag in the slag-cement pastes, and obtained that, under the curing ages of 28 days and 2 years, the hydration degrees of slag in the slag-cement pastes with the water-binder ratio $0.4 \sim 0.6$ and the slag contents $30 \% \sim 60 \%$ are $40 \%$ and $75 \%$, respectively. Taylor [19] carried out the SEM-XRD analysis of the microstructure evolutions of slag-cement pastes cured in water for 20 years, and results show that, the $\mathrm{Ca}(\mathrm{OH})_{2}$ content has a gradual decrease, while the hydration degree of slag in the matrix increases slowly. Zhen [22] examined the influences of slag content on the hydration characteristics of cement paste, and observed that, at high water-binder ratio, the slag-cement pastes with $30 \%$ slag content has the optimum microstructure with the minimum porosity and the most compact structure after the hydration.

The blast furnace slag can effectively improve the microstructure of cement-based materials, and enhance its calcium leaching resistance in water environment [23-25]. Presently, some researches have been carried out to investigate the influences of slag on the calcium leaching behavior of cement-based materials subjected to the attack of the pure water or accelerated solutions [21,24,26-28]. Jain et al. [24] investigated the changes of porosity and calcium hydroxide content in plain and modified cement pastes in pure water with leaching time by using weighing and thermogravimetric method respectively, and obtained that the compactness and calcium hydroxide content in the cement pastes decrease with the leaching time, in which the decrease of compactness, or the increment of porosity is mainly caused by the leaching of calcium hydroxide. Liu[21] utilized Scanning Electron Microscope(SEM) to observe the microstructure morphology of leached slag-cement pastes with water-binder ratio caused by the attack of flowing deionized water, and the evolution characteristics of its microstructure have been revealed in the long-term process of leaching. Due to very slow natural calcium leaching, some accelerated leaching tests on 
cement-based materials have been conducted to investigate the effects of calcium leaching on the materials' performance [29-33]. Yang et al. [27] performed the accelerated leaching experiment to study the influence of calcium leaching on the mechanical properties of cement paste, such as hardness and compressive strength, by using $6 \mathrm{M}$ ammonium chloride solution, and the relationship between mechanical properties and leaching duration has been observed to forecast the compressive strength of the leached cement-based materials on the long term. Wan [28] investigated experimentally the equilibrium curve of $\mathrm{Ca}$ in $6 \mathrm{M}$ ammonium nitrate solution to clarify the accelerated leaching mechanism in cement-based materials, and observed from the comparison between the equilibrium curves of $\mathrm{Ca}$ in $6 \mathrm{M}$ ammonium nitrate solution and in water that they have similar three-staged equilibrium curves, and their dissolving and leaching mechanisms are also similar.

The current studies have revealed the influence mechanism of slag on the hydration characteristics and the initial microstructure of cement-based materials, analyzed the influence of slag on the calcium leaching resistance of cement-based materials in different water environment. But there have been few studies on the optimum mix proportion of slag-cement materials with the best leaching resistance. The optimum mix proportion has an important guiding significance for the design of concrete structures with high resistance to calcium leaching. In order to obtain the optimum mix proportion of slag-cement materials for improving their leaching resistance, the influences of water-binder ratio and slag content on the microstructure evolution of cement-based material and its corrosion resistance in the process of calcium leaching need to be further studied. In this paper, some slice specimens with the slag-cement pastes, which can reduce the influence of calcium ion transport, was designed to carry out an accelerated calcium leaching experiment by using $6 \mathrm{M} \mathrm{NH} \mathrm{NH}_{4} \mathrm{Cl}$ solution, and the influence of slag content and water-binder ratio on the leaching process of the slice specimens were investigated to obtain the optimum leaching resistance. The porosity, material composition, microstructure morphology and Calcium-Silicon ratio of the slag-cement pastes in the process of calcium leaching were tested by using the saturation-drying weighing method, scanning electron microscope (SEM/EDS) and X-ray diffraction(XRD), and by comparing the tested results from the compositional differences at different leaching times, for each slag content and water-binder ratio, some information on the influence of slag content and water-binder ratio on the calcium leaching process were obtained to further ascertain the slag-cement materials with the optimum leaching resistance. 


\section{Experiments}

\subsection{Materials}

The cement used in this study is the 52.5-grade Portland cement, having chemical composition as listed in Table 1 . The density of cement is $3150 \mathrm{~kg} / \mathrm{m}^{3}$, with specific surface area of $369.6 \mathrm{~m}^{2} / \mathrm{kg}$. The initial and final setting time are $72 \mathrm{~min}$ and 290min respectively, and its normal compression strength and flexural strength for 28days curing are 60.5 $\mathrm{MPa}$ and $8.7 \mathrm{MPa}$ respectively. S95-grade blast furnace slag powder with a density of $2.9 \mathrm{~g} / \mathrm{m}^{3}$ and a specific surface area of $435 \mathrm{~m}^{2} / \mathrm{kg}$ was used as an additive mixture. Clean tap water and pure water were used to mix the slag-cement pastes, and prepare the ammonium chloride solution respectively. Table 2 lists the mixture ratio of slag-cement pastes with different water-binder ratio.

\section{Table 1}

Chemical properties of cement and slag. w/\%

\begin{tabular}{ccccccc}
\hline Material & $\mathrm{SiO}_{2}$ & $\mathrm{Al}_{2} \mathrm{O}_{3}$ & $\mathrm{Fe}_{2} \mathrm{O}_{3}$ & $\mathrm{CaO}$ & $\mathrm{MgO}$ & $\mathrm{SO}_{3}$ \\
\hline Cement & 21.1 & 5.56 & 3.98 & 62.48 & 1.76 & 2.59 \\
Slag & 32.7 & 16.1 & 5.54 & 38.7 & 5.5 & 1.46 \\
\hline
\end{tabular}

Table 2

Mixture ratio of slag-cement pastes. (mass content, $\%$ )

\begin{tabular}{|c|c|c|c|c|c|c|c|}
\hline \multirow[t]{2}{*}{ Sample } & \multirow[t]{2}{*}{$\mathrm{m}_{\mathrm{w}} / \mathrm{m}_{\mathrm{b}}$} & \multicolumn{2}{|c|}{ Mass fraction/\% } & \multirow[t]{2}{*}{ Sample } & \multirow[t]{2}{*}{$\mathrm{m}_{\mathrm{w}} / \mathrm{m}_{\mathrm{b}}$} & \multicolumn{2}{|c|}{ Mass fraction/\% } \\
\hline & & Cement & Slag & & & Cement & Slag \\
\hline S0-1 & 0.35 & 100 & 0 & S2-2 & 0.45 & 60 & 40 \\
\hline $\mathrm{S} 1-1$ & 0.35 & 80 & 20 & S3-2 & 0.45 & 50 & 50 \\
\hline S2-1 & 0.35 & 60 & 40 & SO-3 & 0.55 & 100 & 0 \\
\hline S3-1 & 0.35 & 50 & 50 & $\mathrm{~S} 1-3$ & 0.55 & 80 & 20 \\
\hline SO-2 & 0.45 & 100 & 0 & S2-3 & 0.55 & 60 & 40 \\
\hline $\mathrm{S} 1-2$ & 0.45 & 80 & 20 & S3-3 & 0.55 & 50 & 50 \\
\hline
\end{tabular}

Ammonium chloride reagent with a solubility of $37.2 \mathrm{~g} / 100 \mathrm{ml}$ at room temperature was used to prepare the accelerated leaching solution with the concentration of $6 \mathrm{M}$. Similar to the accelerated leaching mechanism of ammonium nitrate solution, the ammonium chloride solution is also a chemical acceleration 
technique, which can be used to establish the long term leaching in cement-based materials[26-27, 33]. The principle of chemically accelerated leaching on cement-based materials is to promote reaction between calcium hydroxide and ammonium chloride in the leachant solution, forming gaseous ammonia and calcium chloride, which is highly soluble in water (see Eq. (1)) [27].

$$
\begin{aligned}
\mathrm{Ca}(\mathrm{OH})_{2}+2 \mathrm{NH}_{4} \mathrm{Cl} & =\mathrm{Ca}^{2+}+2 \mathrm{OH}^{-}+2 \mathrm{H}^{+}+2 \mathrm{NH}_{3}(\uparrow)+2 \mathrm{Cl}^{-} \\
& =\mathrm{CaCl}_{2}+2 \mathrm{NH}_{3}(\uparrow)+2 \mathrm{H}_{2} \mathrm{O}
\end{aligned}
$$

\subsection{Sample preparation and test methods}

According to the mixtures listed in Table 2, One hundred slice specimens with water-binder ratio of three and size $10 \mathrm{~mm} \times 10 \mathrm{~mm} \times 2 \mathrm{~mm}$ were prepared, as shown in Figure 1, and then placed in the curing box at environmental temperature of $(20 \pm 1)^{\circ} \mathrm{C}$ and relative humidity greater than $95 \%$ for curing of 28 -and 90-days respectively. Next, a total of 12 groups were made, with each group containing two 2.5-grams slices in separate nylon-fiber-mesh bags, and then put into 12 water boxes filled with 5 Litres of $6 \mathrm{~mol} / \mathrm{L}$ ammonium chloride solution, as shown in Figure 2.

For the slice specimens with slag-cement pastes subjected to the accelerated leaching, its porosity, pore size and distribution, the changes of which can be used to characterize the leaching process, have very great changes in a relatively short leaching time, but the change of the porosity can be more directly to reflect the leaching degree of cement-based materials than the pore size and distribution. Thus, in this study, the saturation-drying weighing method [24,34], which is a simple and suitable for engineering applications, is used to measure the average porosity to characterize the influences of blast furnace slag and water-binder ratio on the leaching resistance of slag-cement materials. The unleached slice specimens, as well as those leached in ammonium chloride solution for $1,3,5,7,9,12$, or/and 15 days, were subjected to porosity measurements in accordance with the procedure described in the existing document [24]. The SEM observation and XRD phase analysis for the slice specimen immersed into the solution for different leaching time were respectively carried out to investigate the microstructure morphology and mineral composition of the slag-cement pastes [2, 20, 33, 35, 36]. 


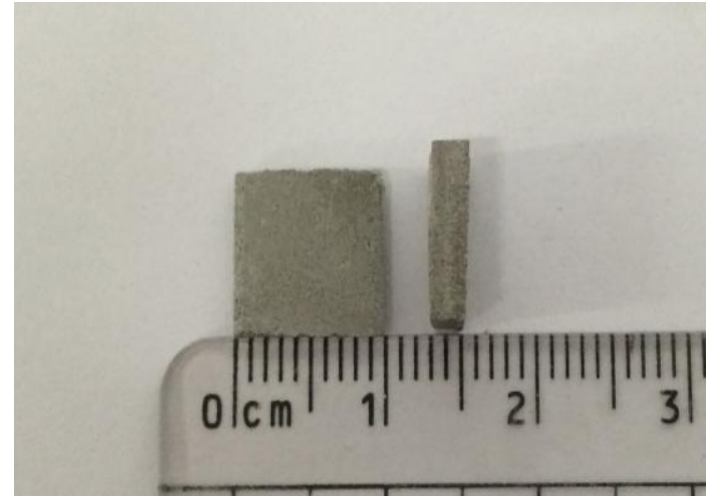

Fig. 1. Slice specimen.

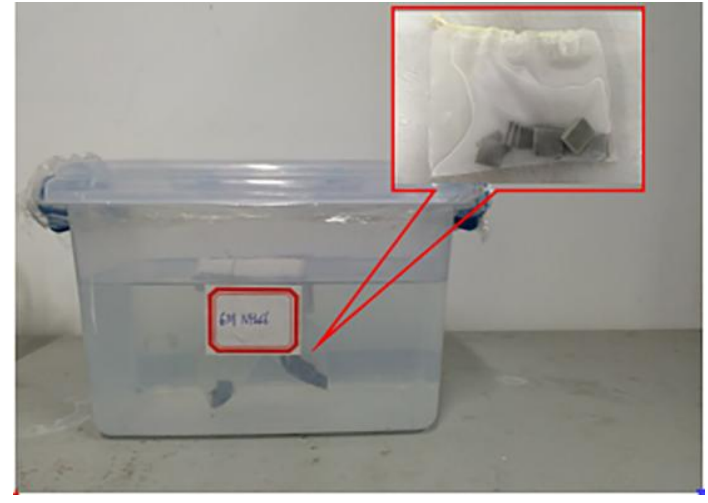

Fig. 2. Experimental setup.

The porosity measurement [24, 34]: the mass of the saturated and dried specimen were measured by high-precision electronic weighing balance $(220 \mathrm{~V}, 50 \mathrm{~Hz})$ with maximum range of $200 \mathrm{~g}$ and accuracy of 0.1mg. The slice specimens were dried using the vacuum drying oven. After each immersion, the slice specimen was removed from the container, and washed under running water. The mass of each saturated surface-dried specimen $\left(\mathrm{m}_{\mathrm{s}}\right)$ was recorded. Then, the mass of specimen suspended in distilled water $\left(\mathrm{m}_{\mathrm{x}}\right)$ was measured by high-precision electronic weighing balance with a built-in type. Finally, the specimens were kept in a vacuum drying oven to dry to constant weight at temperature of $60^{\circ} \mathrm{C}$, and the dried mass $\left(\mathrm{m}_{\mathrm{d}}\right)$ was determined. The average porosity of each specimen $(\varphi)$ was determined from the expression $\varphi=\left(m_{\mathrm{s}}-\mathrm{m}_{\mathrm{d}}\right) /\left(\mathrm{m}_{\mathrm{s}}-\mathrm{m}_{\mathrm{x}}\right) \times 100 \%$

Microscopic observation: the microstructure morphology of fresh fracture surface of slice specimen after accelerated leaching was observed by using a Fei-quanta 200 FEG Scanning Electron Microscope at high vacuum mode. The Energy Dispersive Spectrometer (EDS) was also used to measure the element content on the fresh fracture surface of slice specimen by the linear scan mode.

Phase analysis: the phases in the powder sample from slice specimen in the process of accelerated leaching were analyzed using Bruke X-ray diffractometer, while a LynxEye array detector with high efficiency was applied for X-ray diffractometer. The diffraction pattern was acquired with $\mathrm{Cu} \mathrm{K} \alpha$ radiation operating at $40 \mathrm{kV}$ and $30 \mathrm{~mA}$. Scans were collected at $0.15 \mathrm{~s}$ per step and at a step size of $0.02^{\circ}$ over the 
range from $7^{\circ}$ to $80^{\circ} 2 \theta$. A LynxEye array detector with high efficiency was applied for X-ray detection.

\section{Results and discussion}

\subsection{Porosity}

Porosity is an important parameter to characterize the leaching-induced damage degree and microstructure evolution of cement-based materials subjected to calcium leaching in water environment [5, $16,25,37]$, and the initial porosity of slag-cement paste has a large impact on its calcium leaching process [5, 38]. Figure 3 presents the change of initial porosity of slag-cement pastes with the slag content. It can be obtained from the figure that, for the slice specimens with different water-binder ratios, the initial porosity first decreased and later increased with the slag content, while the minimum initial porosity of slice specimen with different water-binder ratios occurred at $40 \%$ slag content. Thus, the appropriate slag content can reduce the initial porosity of cement paste and effectively improve its microstructure. This is because, in the hydration process of slag-cement system, the hydration of slag absorbs calcium ions in calcium hydroxide to cause the volcanic ash reaction, which consumes calcium hydroxide to generate C-S-H gel with more impact and stable microstructures in the alkaline environment [39, 40]. The pores or the space occupied by the evaporated water are filled with C-S-H gel formed by the slag hydration, and it decreases the porosity of slag-cement pastes. However, the excessively high slag content will reduce the cement content in slag-cement pastes, and result in the decrease of the calcium hydroxide content and the pore solution alkalinity. The low alkalinity of pore solution reduce the slag hydration degree and make slag particle difficult to hydrate in slag-cement system, so the compactness of slag-cement paste decreases as its porosity increases [41-42]. 


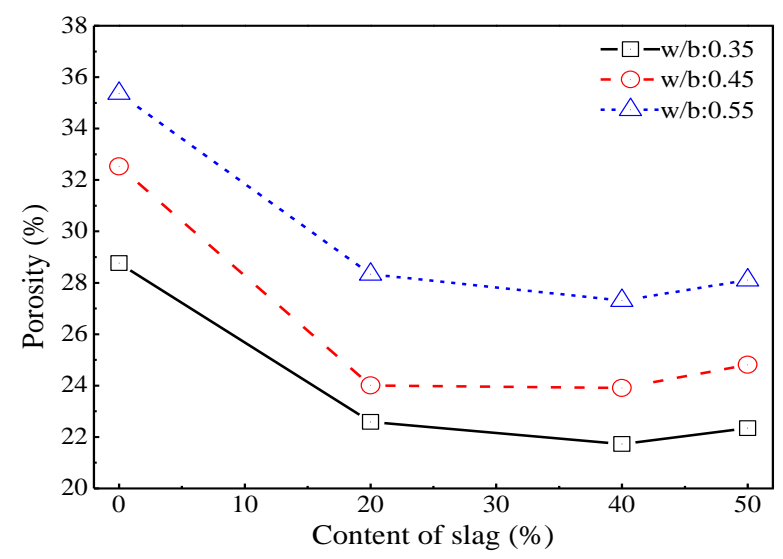

Fig. 3. Changes of initial porosity of slag-cement pastes with content of slag.

In order to investigate the influence of the slag content and water-binder ratio on calcium leaching process of slag-cement pastes, Figure 4 presents the porosity change of slag-cement pastes of different slag contents and water-binder ratios with the leaching time. As seen in the figure, at the early stage of leaching, the porosity of cement pastes with slag content of $0 \%, 20 \%$ and $40 \%$ increases with leaching time, but after accelerated leaching for 6-7 days, the porosity only has a further slight increase. However, for the slag-cement paste with 50\% slag content, its porosity change caused by the leaching is influenced by the water-binder ratio, and the porosity of slag-cement pastes with water-binder of 0.35 and 0.45 have a significant increase with leaching time. The porosity of slag-cement paste with the water-binder ratio of 0.55 increases slowly with leaching time. This is because [43], the calcium hydroxide content is high in the cement-slag pastes with low slag content, and its leaching rate is fast in the early stage of leaching [16]. But in the later stage of leaching, calcium hydroxide in slag-cement pastes has been dissolved out, and the calcium leaching is mainly caused by the dissolution of C-S-H gel, which has a very slow leaching process $[26,28]$. In the case of high slag content, there is low hydration degree in the slag-cement pastes with low water-binder ratio, and in the leaching process, the unhydrated cement or slag continue to hydrate, and the produced calcium hydroxide continuously dissolve, which causes the increase of the porosity with leaching time. 


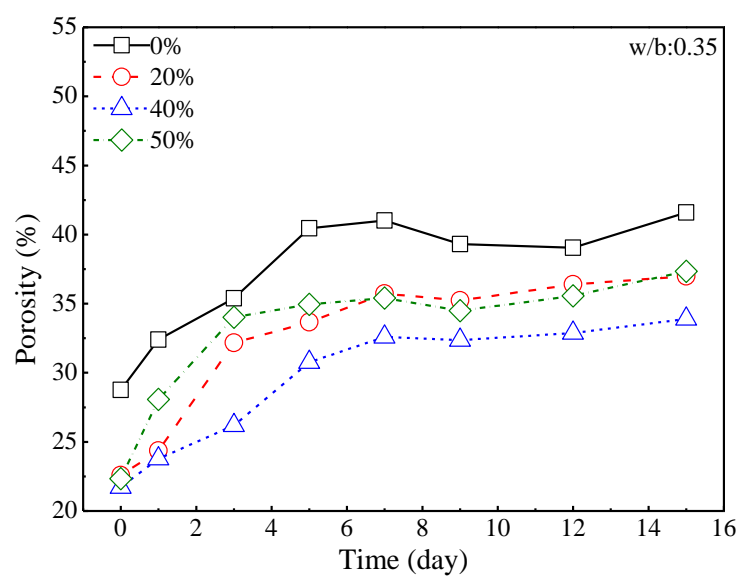

(a)

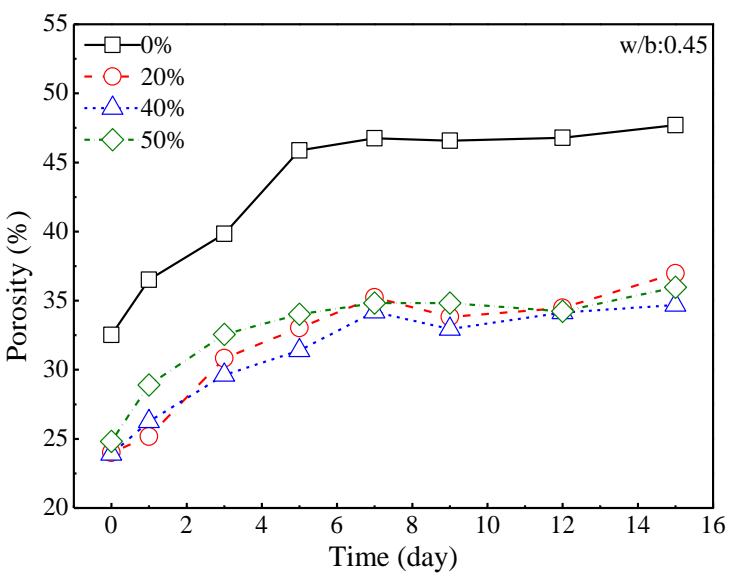

(b)

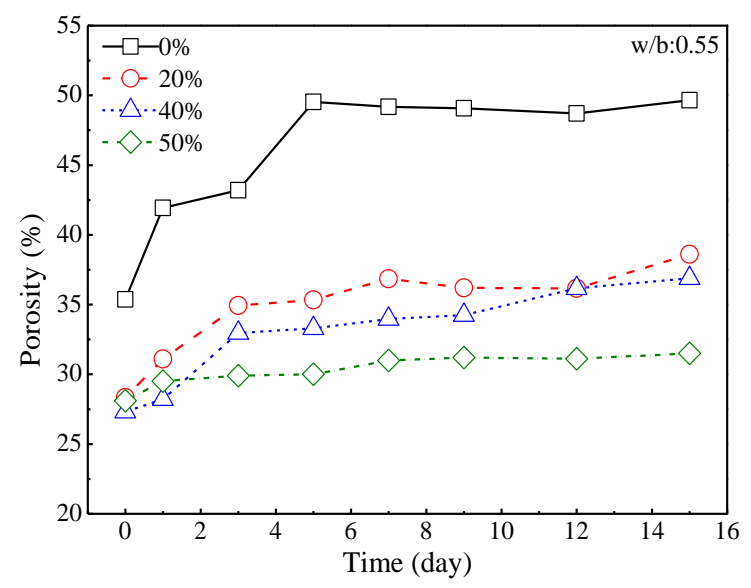

(c)

Fig. 4. Changes of porosity of slag-cement pastes with leaching time. (a) water-binder ratio of 0.35 , (b) water-binder ratio of 0.45 , (c) water-binder ratio of 0.55 .

It can be seen from Figure 4 that, slag mixed in the cement paste at a certain water-binder ratio can improve its compactness and perform the expected leaching resistance, and there exists the optimum slag content with the minimum porosity of slag-cement past, at which an initial decrease but later increase in the leaching process was observed. As shown in Figure 4(a), in the case of slag-cement pastes with water-binder ratio of 0.35 , the porosity decreases with the slag content when the slag content is less than $40 \%$, but increases when the slag content is more than $40 \%$, confirming $40 \%$ slag as the optimum slag content for the leaching resistance of the slag-cement paste with water-binder of 0.35 . Furthermore, by comparing the porosity change of slag-cement paste with different water-binder ratios under the condition of the same slag content, it was observed that the reduction of water-binder ratio improved the compactness and initial porosity of slag-cement pastes, and decreased the diffusion rate of calcium ions in pore solution, 
leading to an enhanced calcium leaching resistance. This further indicates that the optimum slag content for the leaching resistance of slag-cement pastes is also associated with its water-binder ratio [14].

\subsection{Phase}

To investigate the influence of slag content on the chemical composition in cement pastes, such as calcium hydroxide and C-S-H gel, Figure 5 presents the XRD patterns of unleached slag-cement paste samples with water-binder ratio of 0.45 and slag content of $0 \%, 20 \%$ and $50 \%$. It can be seen from the figure that, the two diffraction peak values of calcium hydroxide in each sample at $2 \theta=18.06^{\circ}$ and $2 \theta=34.14^{\circ}$ decreased with the increase of slag content, and the diffraction peak value of calcium hydroxide in the sample with 50\% slag is only one fifth of that in the sample with $0 \%$ slag. Compared with the samples with $0 \%$ and $20 \%$ slag, the diffraction peak of calcium sulfoaluminate hydrates(AFt) at $2 \theta=9.65^{\circ}$ cannot be clearly observed in the XRD pattern of the sample with $50 \%$ slag, but the diffraction peak of calcium monosulfate aluminate hydrates (AFm) can be observed, and it can be seen from the XRD pattern that the calcium-silicon ratio is 1.17 which is less than the calcium-silicon ratio(1.50) observed in the XRD patterns of the samples with $0 \%$ and $20 \%$ slag. Therefore, slag mixed in cement pastes can change the chemical composition of its hydrated products, and decrease the calcium hydroxide content and calcium-silicon ratio of C-S-H gel, which is helpful in improving the leaching resistance of cement pastes.

The reason for this is that, the cement content in slag-cement pastes is relatively lower than that in cement pastes without slag, so the calcium hydroxide content in slag-cement pastes produced by the hydration process decreases. The secondary hydration of slag leads to the consumption of more calcium hydroxide in slag-cement paste, the higher the slag content, the more calcium hydroxide consumed in the second hydration reaction of slag $[42,44]$. Thus, in the cement pastes with extremely high slag content, the 
calcium hydroxide produced by the cement hydration will not be sufficient for the slag hydration reaction $[39,45]$. Additionally, in the hydration reaction of slag-cement pastes, dicalcium aluminate silicate $\left(\mathrm{C}_{2} \mathrm{AS}\right)$ and aluminate, produced by the hydration of the active $\mathrm{Al}_{2} \mathrm{O}_{3}$ in the slag, have further reactions with calcium sulfoaluminate hydrates (AFt) to generate calcium monosulfate aluminate hydrates (AFm) $[21,46]$.

In order to analyze comparatively the change of phases such as calcium hydroxide and C-S-H gel in cement-based materials in the process of accelerated leaching, Figure 6 shows the XRD patterns of the cement paste samples with water-binder ratio of 0.45 before and after accelerated leaching for 5-and 9-days. It can be seen from the diffraction peaks of calcium hydroxide and C-S-H in the patterns that, before the leaching, there exist lots of calcium hydroxide and C-S-H phases with calcium-silicon ratio of 1.5 , as well as a little unhydrated cement clinker such as $\mathrm{C}_{2} \mathrm{~S}$ and $\mathrm{C}_{3} \mathrm{~S}$ in the samples. However, after accelerated leaching for 5days, the diffraction peak of calcium hydroxide is difficult to observe, but the diffraction peak of C-S-H phases with calcium-silicon ratio of 1.50 still exists in the XRD patterns of the samples. This indicates that, for 5 days of accelerated leaching, calcium hydroxide in the samples has been leached out , but the decalcification and dissolution of C-S-H phases has not occurred. The above results of C-S-H phase in XRD patterns are consistent with that of the porosity measurements shown in Figure 4(b). In contrast, after accelerated leaching for 9days, the calcium-silicon ratio in C-S-H phase obtained from the XRD patterns decreased from 1.50 in the unleached samples to 1.00 or 0.83 for the leached samples, indicating clearly that the cement paste slice specimen has undergone calcium leaching. 


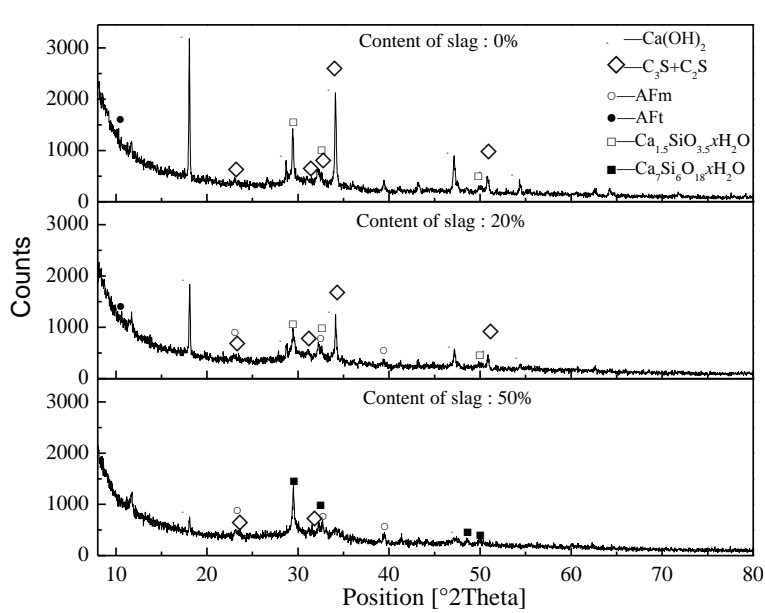

Fig. 5. XRD patterns of hardened pastes before leaching.

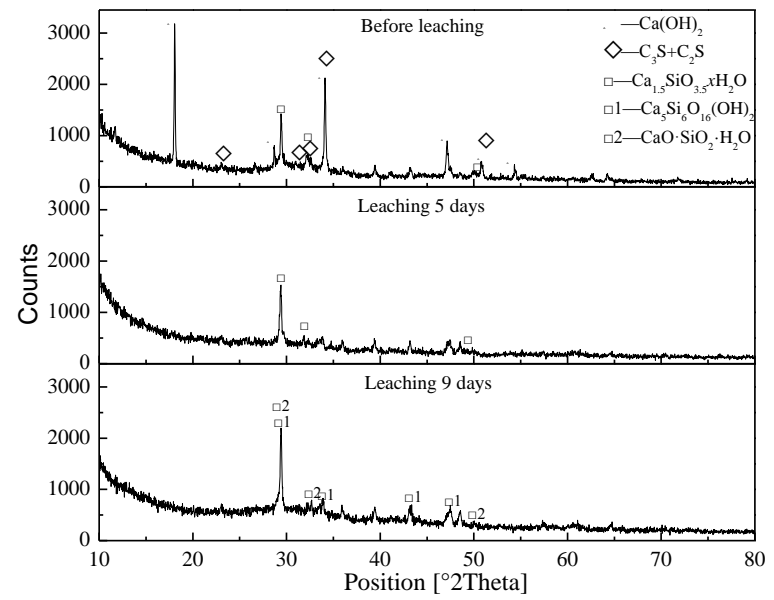

Fig. 6. XRD patterns of hardened pastes with different leaching times.

\subsection{Calcium-Silicon ratio $(\mathrm{Ca} / \mathrm{Si})$}

After calcium and silicon in cement-based materials are dissolved in the water environment, they exist in pore solution in the form of calcium ions and silicate ions. But compared with calcium ions, silicate ions occupy only small portion, and its dissolution rate is extremely slow. Due to great difference between the dissolution rates of calcium ions and silicate ions, the changes in Calcium-Silicon ratio $(\mathrm{Ca} / \mathrm{Si})$ can be used to characterize the calcium leaching process of cement-based materials in water environments [28]. For this purpose, the Electron Probe of Scanning Electron Microscope was performed to linearly scan the fresh fracture surface of slice specimen and analyze the changes in its chemical composition with the slag content and water-binder ratio. Based on the scanning results of its chemical composition, the expression $\mathrm{Ca} / \mathrm{Si}=\left(\mathrm{n}_{\mathrm{Ca}} \times \mathrm{M}_{\mathrm{Ca}}\right) /\left(\mathrm{n}_{\mathrm{Si}} \times \mathrm{M}_{\mathrm{Si}}\right)$ was used to calculate the distribution of calcium-silicon ratio on the fracture surface of slice specimens subjected to calcium leaching. Calcium-Silicon ratio $(\mathrm{Ca} / \mathrm{Si})$ represents the mass ratio of calcium and silicon, while $\mathrm{n}_{\mathrm{Ca}}, \mathrm{n}_{\mathrm{Si}}$ and $\mathrm{M}_{\mathrm{Si}}, \mathrm{M}_{\mathrm{Ca}}$ are respectively the molar numbers and relative atomic masses of $\mathrm{Ca}$ and $\mathrm{Si}$. The change of $\mathrm{Ca} / \mathrm{Si}$ in slag-cement pastes with $40 \%$ slag after accelerated leaching for 0-, 3- and 15-days is presented in Figure 7, where the dotted lines indicate the average value of $\mathrm{Ca} / \mathrm{Si}$ on the fracture surface of slice specimen. It can be seen from the figure that the peak and average values of $\mathrm{Ca} / \mathrm{Si}$ in unleached slag-cement pastes with different water-binder ratios are obviously greater than that in the leached slice specimens, but they gradually decrease with increase in leaching time. After leaching for 3 days, it was observed that $\mathrm{Ca} / \mathrm{Si}$ is low at the surface edge and high in the middle of the surface of the slice specimen with water-binder ratio of 0.35 , but for the slice specimen with water-binder 
ratios of 0.45 and $0.55, \mathrm{Ca} / \mathrm{Si}$ is low on its whole surface. However, after leaching for 15 days, $\mathrm{Ca} / \mathrm{Si}$ on the surface of each specimen changed from 1.0 to 1.25 , with uniform distribution. The change of $\mathrm{Ca} / \mathrm{Si}$ in the slice specimens with $0 \%$ and $50 \%$ slag with leaching time is similar to that of $40 \%$ slag.

Figure 8 presents the change of the average $\mathrm{Ca} / \mathrm{Si}$ on the fracture surface of each slice specimen with different slag content and water-binder ratio with the leaching time. It can be seen from the figure that, $\mathrm{Ca} / \mathrm{Si}$ on the surface of each slice specimen decreases with increase in leaching time. In the case of the 0.45 water-binder ratio, after leaching for 15 days, its average $\mathrm{Ca} / \mathrm{Si}$ decreased by 3.7 , indicating that the average $\mathrm{Ca} / \mathrm{Si}$ in the slice specimen without slag had the most significant reduction in the entire leaching process. But for the slice specimen with $40 \%$ slag, its average $\mathrm{Ca} / \mathrm{Si}$ obviously decreased in the first 3 days of leaching, but only experienced a slight decrease in the later leaching period, with a decrease value of 1.91 . The average $\mathrm{Ca} / \mathrm{Si}$ of slice specimen with $50 \%$ slag has a well-proportioned and slow decrease, and the decrease value for 15 days of leaching is 1.65 . The average $\mathrm{Ca} / \mathrm{Si}$ of all slice specimens is less than 1.27 after accelerated leaching for 15 days, in which the decrease value of slice specimen with $50 \%$ slag is the smallest.

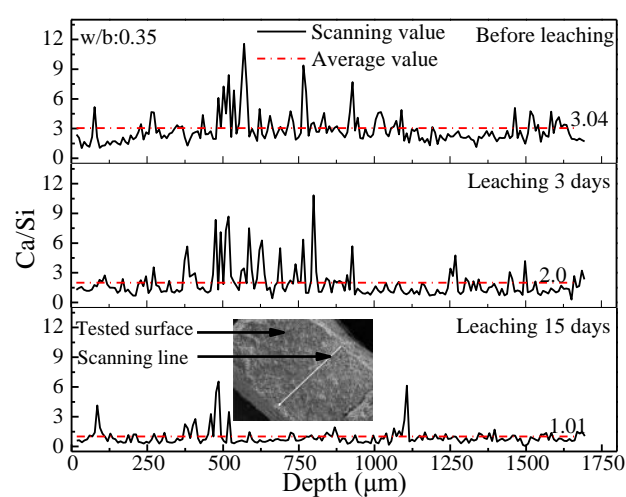

(a)

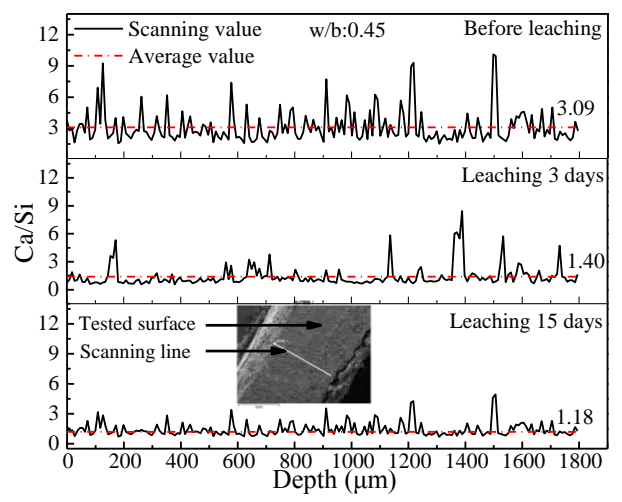

(b)

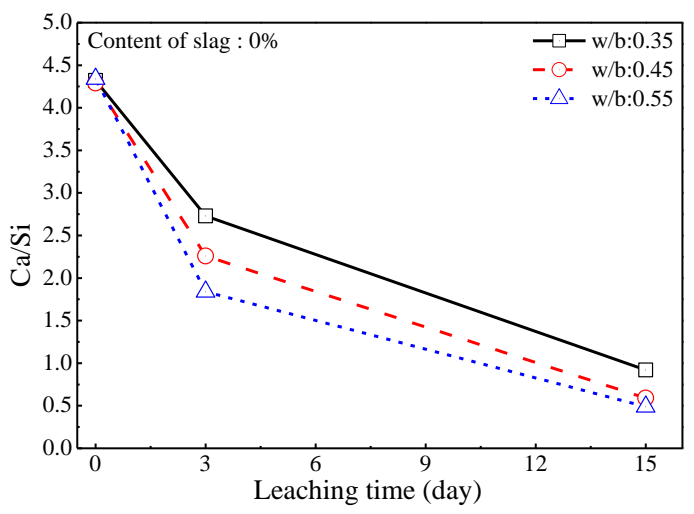

(a)

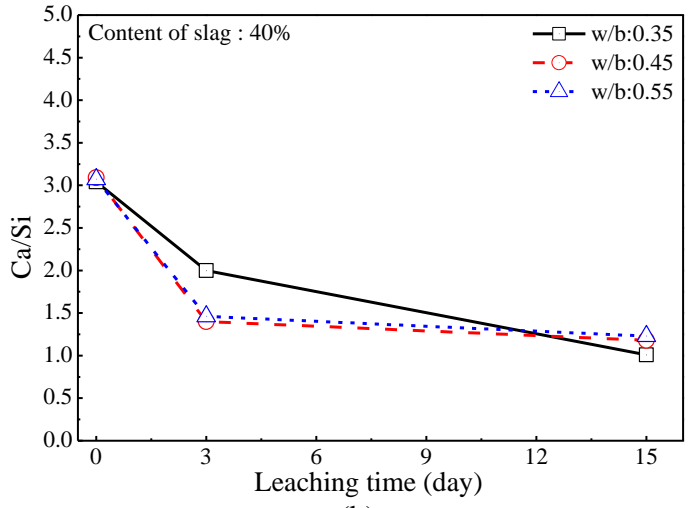

(b) 


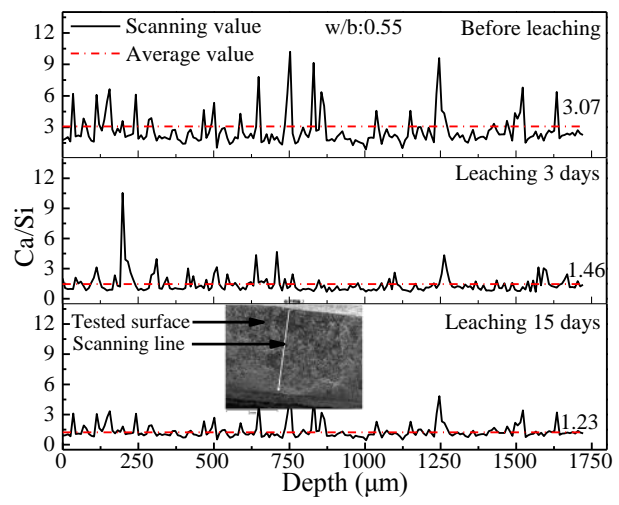

(c)

Fig. 7. Change of $\mathrm{Ca} / \mathrm{Si}$ in the matrix with $40 \%$ slag.

(a) water-binder ratio of 0.35 , (b) water-binder ratio of 0.45 , (c) water-binder ratio of 0.55 .

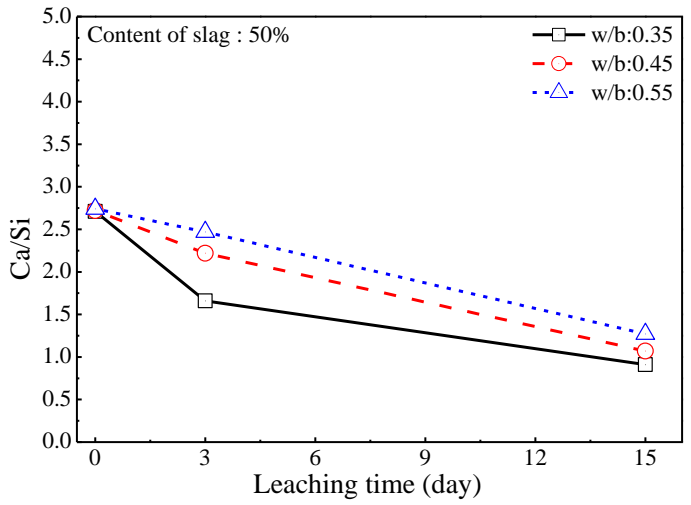

(c)

Fig. 8. Change of average $\mathrm{Ca} / \mathrm{Si}$ with leaching time.

(a) with no slag, (b) with $40 \%$ slag, (c) with $50 \%$ slag.

\subsection{Microstructure morphology}

In order to determine the influence of slag on the microstructure of slag-cement paste, The Scanning Electron Microscopy (SEM) was used to observe the morphology of unleached and leached slag-cement pastes with different slag content and water-binder ratio. Figure 9 shows the microstructure morphology of the unleached and leached slag-cement pastes with $0 \%$ and $40 \%$ slag contents, whose water-binder ratio is 0.45. It can be seen from the figure that, for the unleached slice specimen, its microstructure when mixed with slag is more compact than that without slag, and many plate-like calcium hydroxide crystals and flocculent C-S-H gel grow criss-crossedly on the slice specimen with no slag, and a little of needle ettringite appear in the pore of C-S-H gel. The slice specimen with $40 \%$ slag also contain some calcium hydroxide crystals, C-S-H gel and some unhydrated slag particles, which are in close contact with the surrounding cement paste [47], and this observation is consistent with the measured results from the porosity in Figure 3 and XRD phase in Figure 5 for unleached slice specimens. After accelerated leaching for 3 days, the microstructure of slice specimen with no slag is loose and porous, with many loose products, while the calcium hydroxide crystals obviously decreased. However, the microstructure of slag-cement pastes with slag remained compact, with very little loose products, and more close contact between the unhydrated slag particles and the surrounding matrix are observed. The microstructure morphologies shown in Figure 9 further demonstrate that the slag mixed in cement pastes can increase compactness, slow down leaching process, and effectively improve its leaching resistance [21, 45]. 
The water-binder ratio is also an important factor influencing the leaching process of slag-cement pastes [14]. Figure 10 shows the influence of water-binder ratios, 0.35 and 0.55 , on the microstructure morphology of unleached and leached slag-cement pastes with $0 \%$ and $40 \%$ slag contents. It can be observed from Figure 10(a) that the compactness of C-S-H gel generated by the hydration of slag-cement pastes with water-binder ratio of 0.35 is greater than that with water-binder ratio of 0.55 [46]. At same slag content, the average porosity of slag-cement pastes with lower water-binder ratio is less than that with higher water-binder ratio [48, 49], and this observation is similar to the results in Figure 3. As shown in Figure 10(b), after 3 days accelerated leaching of the slice specimen with water-binder ratio of 0.35 , some calcium hydroxide crystals can be still be observed, and the morphology of C-S-H gel did not change. However, in the slice specimen with water-binder ratio of 0.55 , the calcium hydroxide crystals cannot be observed, while the C-S-H gel became loose. From the distribution of $\mathrm{Ca} / \mathrm{Si}$ on the fracture surface of the slice specimen, it was observed that the calcium leaching degree in slag-cement pastes with lower water-binder ratio is less than that with higher water-binder ratio, and this observation is similar to the results from the average $\mathrm{Ca} / \mathrm{Si}$ shown in Figure 8. From the result of the microstructure evolution between unleached and leached slag-cement pastes, Figure 10 confirms that the reduction of water-binder ratio will improve the microstructure of slag-cement pastes, increase its compactness, and effectively improve the leaching resistance of slag-cement pastes.
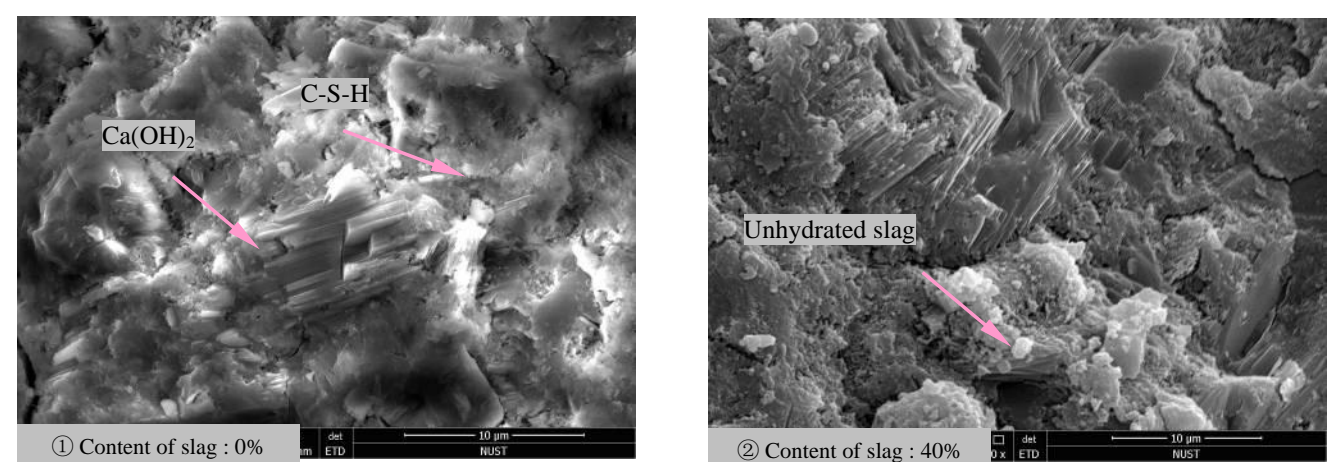

(a) 

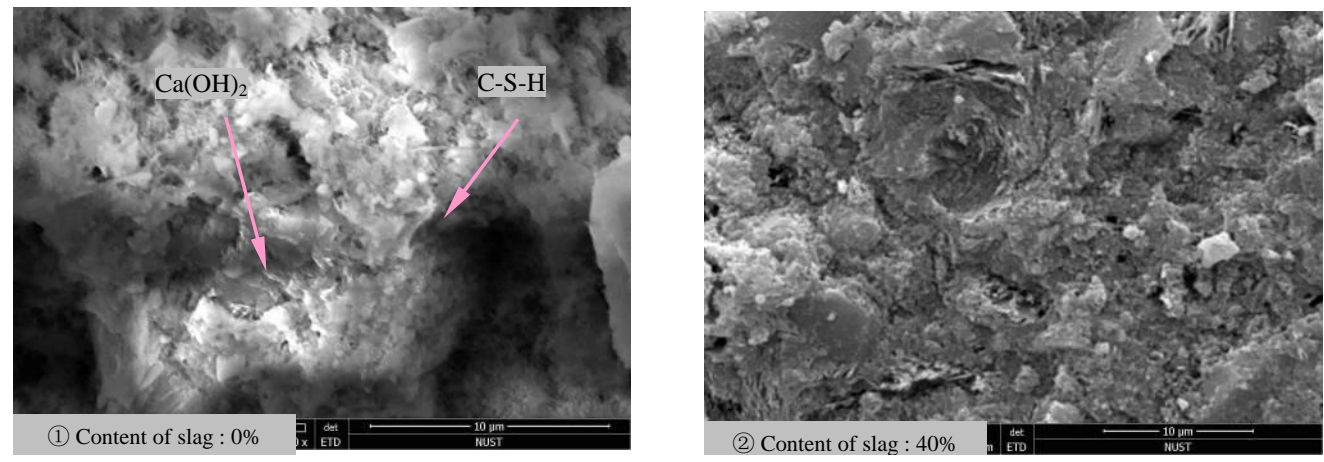

(b)

Fig. 9. Influence of slag content on morphology of unleached and leached specimen with w/b of 0.45 . (a) before leaching, (b) leaching 3 days.
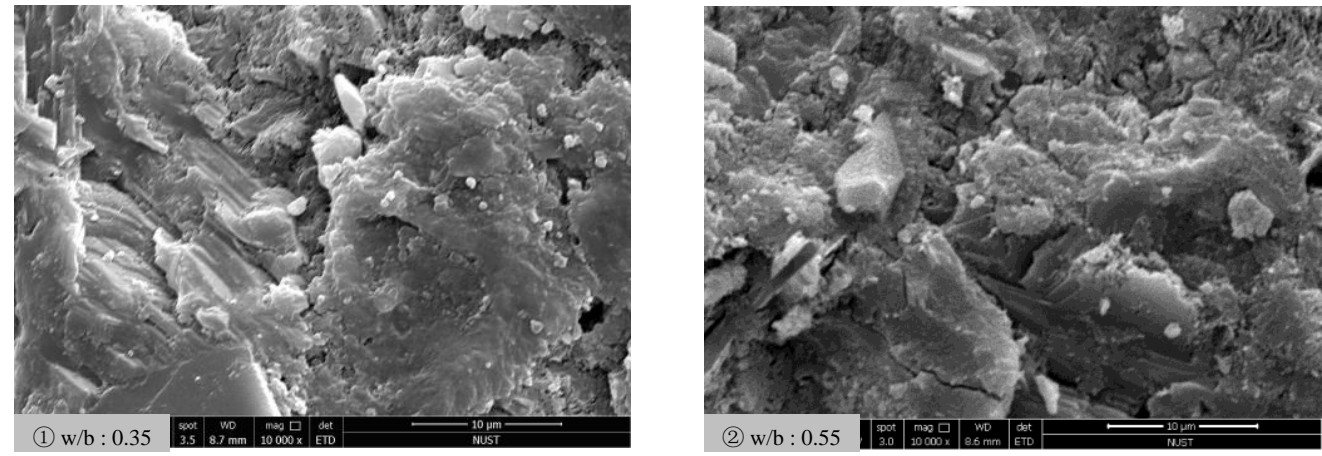

(a)
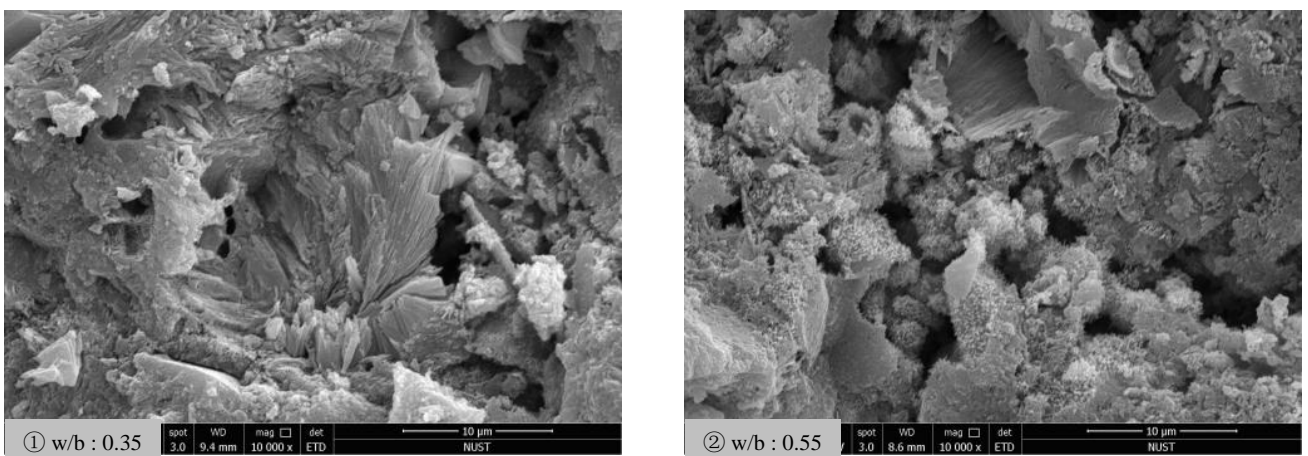

(b)

Fig. 10. Influence of water-binder ratio on morphology of unleached and leached specimen with $40 \%$ slag. (a) before leaching, (b) leaching 3 days.

\section{Conclusions}

The accelerated leaching experiment on slag-cement slice specimens immersed into $6 \mathrm{M} \mathrm{NH}_{4} \mathrm{Cl}$ solution was carried out to investigate the changes of the porosity, phase composition, morphology and $\mathrm{Ca} / \mathrm{Si}$ of slag-cement pastes with different slag content and water-cement ratio with the leaching time by using saturation-drying weighing method, X-ray diffraction analysis (XRD) and Scanning Electron 
Microscopy (SEM) respectively. The following conclusions were made: (1) The porosity of the cement pastes with no slag increases with the water-binder ratio, while the porosity, calcium hydroxide content and $\mathrm{Ca} / \mathrm{Si}$ of the unleached slag-cement pastes are less than that without slag. (2) The higher slag content in slag-cement system result in lower calcium hydroxide content and $\mathrm{Ca} / \mathrm{Si}$ in the slice specimen. The compactness, calcium hydroxide content and $\mathrm{Ca} / \mathrm{Si}$ decrease with the increase of leaching time, and the reduction rate of unleached matrix with slag is less than that without slag. (3) The slag-cement pastes with $40 \%$ slag and low water-binder ratio, or with $50 \%$ slag and high water-binder ratio has the optimum calcium leaching resistance. (4) Thus, the appropriate slag content and water-binder ratio can slow down the microstructure deterioration of slag-cement pastes and calcium leaching process, and effectively improve its leaching resistance.

\section{Acknowledgements}

The study of this paper is financially supported by National Science Foundation of China (51378262)

and by Jiangsu Province Science Foundation (BK20141396).

\section{Reference}

[1] Bellego L, Gerard B, Pijaudier-Cabot G. Mechanical analysis of concrete structures submitted to an aggressive water attack. Fract Mech Concr Struct 2001; 1(2): 239-246.

[2] Rozière E, Loukili A. Performance-based assessment of concrete resistance to leaching. Cem Concr Compos 2011; 33(4): 451-456.

[3] El-Dakroury A, Ibrahim I, Iyob I. Assessment of changes in physical characteristics due to leaching of hydration products from concrete. Adv Cem Res 2011; 23(2): 61-67.

[4] Garde C, Franqois R, Jean-Michel. Leaching of both calcium hydroxide and C-S-H from cement paste: Modeling the mechanical behavior. Cem Concr Res 1996; 28(6): 1257-1268.

[5] Haga K, Sutou S, Hironaga M, Tanaka S, Nagasaki S. Effects of porosity on leaching of Ca from hardened ordinary Portland cement paste. Cem Concr Res 2005; 35(9): 1764-1775.

[6] Choi YS, Yang EI. Effect of calcium leaching on the pore structure, strength, and chloride penetration resistance in concrete specimens. Nucl Eng Des 2013; 259: 126-136.

[7] Roziere E, Loukili A. Performance-based assessment of concrete resistance to leaching. Cem Concr Compos 2011; 33(4): 451-456.

[8] Haga K, Sutou S, Hironaga M, Tanaka S, Nagasaki S. Effects of porosity on leaching of Ca from hardened ordinary Portland cement paste. Cem Concr Res 2005; 35(9): 1764-1775.

[9] Le Bellego C, Pijaudier-Cabot G, Gerard B, Dube JF, Molez L. Coupled mechanical and chemical damage in calcium leached cementitious structures. J Eng Mech 2003; 129(3): 333-341.

[10] Le Bellego C, Gerard B, Pijaudier-Cabot G. Mechanical analysis of concrete structures submitted to an 
aggressive water attack. Fract Mech Concr Struct 2001. 239-246.

[11] Wang X, Lee H, Park K, Kim J, Golden JS. A multi-phase kinetic model to simulate hydration of slag-cement blends. Cem Concr Res 2010; 32(6): 468-477.

[12] Wang X, Lee H. Modeling the hydration of concrete incorporating fly ash or slag. Cem Concr Res 2010; 40(7): 984-996.

[13] Reginald B, Kogbara, Abir A. Mechanical and leaching behaviour of slag-cement and lime-activated slag stabilised/solidified contaminated soil. Sci Total Environ 2011; 409(11): 2325-2335.

[14] Yio MHN, Phelan JC, Wong HS, Buenfeld NR. Determining the slag fraction, water/binder ratio and degree of hydration in hardened cement pastes. Cem Concr Res 2014; 56:171-181.

[15] Müllauer W, Beddoe RE, Heinz D. Leaching behaviour of major and trace elements from concrete: Effect of fly ash and GGBS. Cem Concr Res 2015; 58: 129-139.

[16] Wan K, Li L, Xu Q, Sun W. Spatial distribution of the increased porosity of cement paste due to calcium leaching. J Wuhan Univ Technol 2015; 30(4): 735-744.

[17] Vance K, Aguayo M, Dakhane A, Ravikumar D, Jitendra J, Narayanan N. Microstructural, Mechanical, and Durability Related Similarities in Concretes Based on OPC and Alkali-Activated Slag Binders. Int J Concr Struct M 2014; 8(4): 289-299.

[18] Lumley JS, Gollop RS, Moir GK, Taylor HFW. Degrees of reaction of the slag in some blends with Portland cements. Cem Concr Res 1996; 26(1): 139-151.

[19] Taylor R, Richardson IG, Brydson RMD. Composition and microstructure of 20-year-old ordinary Portland cement-ground granulated blast-furnace slag blends containing 0 to $100 \%$ slag. Cem Concr Res 2010; 40(7): 971-983.

[20] López MM, Pineda Y, Gutiérrez O. Evaluation of Durability and Mechanical Properties of the Cement Mortar Added with Slag Blast Furnace. Procedia Mater Sci 2015; 9: 367-376.

[21] LIU R, ZHANG B, YAN P. Microstructural Variation of Hardened Cement-slag Pastes Leached by Soft Water. J Chin Ceram Soc 2013(11): 1487-1492.

[22] Keren Z, Wei S, Yantao J, Yunsheng Z, Liping G. Effects of slag dosage on hydration products and pore structure of cement paste at high water to binder ratio. J Chin Ceram Soc 2005; 33(04): 520-524.

[23] Nguyen VH, Colina H, Torrenti JM, Boulay C, Nedjar B. Chemo-mechanical coupling behaviour of leached concrete Part 1: Experimental results. Nucl Eng Des 2007; 237(20-21): 2083-2089.

[24] Jain J, Neithalath N. Analysis of calcium leaching behavior of plain and modified cement pastes in pure water. Cem Concr Compos 2009; 31(3): 176-185.

[25] El-Dakroury A, Ibrahim IS, Iyob IE. Assessment of changes in physical characteristics due to leaching of hydration products from concrete. Adv Cem Res 2011; 23(2): 61-67.

[26] Nakarai K, Ishida T, Maekawa K. Modeling of Calcium Leaching from Cement Hydrates Coupled with Micro-Pore Formation. J Adv Concr Technol 2006; 4(3): 395-407.

[27] Yang H, Jiang L, Zhang Y, Pu Q, Xu Y. Predicting the calcium leaching behavior of cement pastes in aggressive environments. Constr Build Mater 2012; 29: 88-96.

[28] Wan K, Li L, Sun W. Solid-liquid equilibrium curve of calcium in 6mol/L ammonium nitrate solution. Cem Concr Res 2013; 53: 44-50.

[29] Heukamp FH, Ulm FJ, Germaine JT. Mechanical properties of calcium-leached cement pastes: Triaxial stress states and the influence of the pore pressures. Cem Concr Res 2001; 31(5): 767-774.

[30] Hu Y, Linhua J, Yan Z, Qi P, Yi X. Predicting the calcium leaching behavior of cement pastes in aggressive environments. Constr Build Mater 2012; 29: 88-96.

[31] Keshu W, Yan L, Wei S. Experimental and modelling research of the accelerated calcium leaching of 
cement paste in ammonium nitrate solution. Constr Build Mater 2013; 40: 832-846.

[32] Quoc TP, Maes N, Jacques D, De Schutter G, Ye G. Microstructural and permeability changes due to accelerated $\mathrm{Ca}$ leaching in ammonium nitrate solution. $5^{\text {th }}$ International Conference on Concrete Repair. Belfast, UK. 2014. 431-438.

[33] Forster AM, Szadurski EM, Banfill PFG. Deterioration of natural hydraulic lime mortars, I: Effects of chemically accelerated leaching on physical and mechanical properties of uncarbonated materials. Constr Build Mater 2014; 72: 199-207.

[34] CPC R. Absorption of water by immersion under vacuum. Mater Struct 1984; 17: 391-394.

[35] Ulm F, Lemarchand E, Heukamp FH. Elements of chemomechanics of calcium leaching of cement-based materials at different scales. Eng Fract Mech 2003; 70(7): 871-889.

[36] Lin W, Cheng A, Huang R, Chen C, Zhou X. Effect of Calcium Leaching on the Properties of Cement-based Composites. J Wuhan Univ Technol 2011; 26(5): 990-997.

[37] Han F, Liu R, Yan P. Effect of fresh water leaching on the microstructure of hardened composite binder pastes. Constr Build Mater 2014; 68: 630-636.

[38] Wan K, Xu Q, Li L, Sun W. 3D porosity distribution of partly calcium leached cement paste. Constr Build Mater 2013; 48: 11-15.

[39] Richardson IG, Groves GW. Microstructure and microanalysis of hardened cement pastes involving ground granulated blast-furnace slag. J Mater Sci 1992; 27(22): 6204-6212.

[40] Radwan AM, Elalfi EA, Osman RM. Characteristics of Portland cement pastes with high replacement of slag. JEAS 2012; 7(3): 338-344.

[41] Chen W, Brouwers HJH. The hydration of slag, part 1: reaction models for alkali-activated slag. J Mater Sci 2007; 42(2): 428-443.

[42] Fernández-Jiménez A, Puertas F. Alkali-activated slag cements: Kinetic studies. Cem Concr Res 1997; 27(3): 359-368

[43] Hadj-Sadok A, Kenai S, Courard L, Darimont A. Microstructure and durability of mortars modified with medium active blast furnace slag. Constr Build Mater 2011; 25(2): 1018-1025.

[44] Roziere E, Loukili A, El Hachem R, Grondin F. Durability of concrete exposed to leaching and external sulphate attacks. Cem Concr Res 2009; 39(12): 1188-1198.

[45] Cheng A, Chao S, Lin W. Effects of Leaching Behavior of Calcium Ions on Compression and Durability of Cement-based Materials with Mineral Admixtures. Materials 2013; 6(5): 1851-1872.

[46] Sun W. Durability evaluation and service life prediction of modern concrete. Bei Jing: China Building Industry Press, 2015.

[47] Garg M, Pundir A. Investigation of properties of fluorogypsum-slag composite binders - Hydration, strength and microstructure. Cem Concr Compos 2014; 45: 227-233.

[48] Stora E, Bary B, He QC, Deville E, Montarnal P. Modelling and simulations of the chemo-mechanical behaviour of leached cement-based materials: Interactions between damage and leaching. Nucl Instrum Meth 2010; 40(40): 1226-1236.

[49] Kim TW, Hahm HG, Lee SH, Eom JS. The Fundamental Properties of Alkali-Activated Slag Cement (AASC) Mortar with Different Water-Binder Ratios and Fine Aggregate-Binder Ratios. Imperial College London 2013; 17(5): 77-86. 